\title{
The influence of framing on transfer: initial evidence from a tutoring experiment
}

\author{
Randi A. Engle • Phi D. Nguyen • Adam Mendelson
}

Received: 8 December 2009/Accepted: 14 July 2010/Published online: 31 July 2010

(C) The Author(s) 2010. This article is published with open access at Springerlink.com

\begin{abstract}
This paper investigates the idea that the framing of learning and transfer contexts can influence students' propensity to transfer what they have learned. We predicted that transfer would be promoted by framing contexts in an expansive manner in which students are positioned as having the opportunity to contribute to larger conversations that extend across time, places, people, and topics. A one-on-one tutoring experiment was conducted to test this hypothesis by manipulating framing as either expansive or its opposite (bounded) within a complex instructional learning ecology. We investigated the degree to which high school biology students transferred knowledge from a learning session about the cardiovascular system to a transfer-of-learning session about the respiratory system depending on framing condition. Consistent with the framing hypothesis, students in the expansive condition were generally more likely to transfer facts, a conceptual principle, and a learning strategy from one system to another.
\end{abstract}

Keywords Transfer-of-learning · Human tutoring · Framing ·

Social interactions and learning $\cdot$ Self-explaining

Transfer-of-learning, or the application of something that has been learned in one context to another context, is one of the most important educational phenomena. Without it, what students learn in school and elsewhere would have little effect on the rest of their lives. Transfer is also one of the most longstanding and difficult research topics in education and psychology (Barnett and Ceci 2002; Detterman and Sternberg 1993; Gick and Holyoak 1983; Judd 1908; Lave 1988; Lobato 2006; Salomon and Perkins 1989; Thorndike and Woodworth 1901). As Barnett and Ceci (2002) explained, "there is little agreement in the scholarly community about the nature of transfer, the extent to which it occurs, and the nature of its underlying mechanisms" (p. 612).

R. A. Engle $(\bowtie) \cdot$ P. D. Nguyen · A. Mendelson

Graduate School of Education, University of California, Berkeley,

4646 Tolman Hall, Berkeley, CA 94720-1620, USA

e-mail: RAEngle@berkeley.edu 
This paper focuses on the issue of instructional mechanisms. In an earlier article, Engle (2006) used a detailed case study from a Fostering Communities of Learners classroom to further specify and illustrate a proposed instructional mechanism for influencing transfer that has rarely been studied empirically: How the social contexts in which learning and transfer could occur are framed. In this paper, we report the first systematic test of this mechanism: a tutoring experiment designed to see whether manipulating framing in the ways discussed by Engle (2006) does actually affect students' propensity to transfer.

\section{Framing contexts as a mechanism for transfer}

Most research on transfer mechanisms does not focus on issues of context or its framing, but instead on the academic content that students are to transfer (Mestre 2003; Reeves and Weisberg 1994; Schwartz and Nasir 2003). Researchers emphasize the importance of students fully learning the content they are supposed to transfer (Bransford et al. 1999), being provided with enough examples of that content (Gick and Holyoak 1983; Mestre 2003), comparing examples to form generalizations at the right level of abstraction (Gentner et al. 2003; Rittle-Johnson and Star 2007), and coordinating generalizations with the particular features of specific examples (Reeves and Weisberg 1994; Wagner 2006).

When context is addressed in research on transfer mechanisms ${ }^{1}$ the focus is on physical realities, like the physical location in which learning or transfer sessions are conducted, what people and materials are present, and the like (Barnett and Ceci 2002; Catrambone and Holyoak 1989; Spencer and Weisberg 1986; Thorndike 1903/2009; Reeves and Weisberg 1994). Many studies have shown that transfer is more likely when such physical features overlap between learning and transfer contexts (Barnett and Ceci 2002; Catrambone and Holyoak 1989; Reeves and Weisberg 1994; Ross 1984; Spencer and Weisberg 1986). Classical cognitive accounts explain this finding by assuming that contextual features are stored in memory with learned content, and contextual overlaps then prime or cue recall of the relevant content (Anderson and Bower 1973; Godden and Baddeley 1975, 1980; Reeves and Weisberg 1993; Ross 1984; Smith et al. 1978; Tulving and Thomson 1973).

Our approach to contextual effects on transfer moves beyond purely physical conceptualizations in ways consistent with suggestions made by situative and sociocultural theorists (Brown 1989; Greeno 2006; Greeno et al. 1993; Laboratory of Comparative Human Cognition [LCHC] 1983; Lave 1988; Lemke 2001; Pea 1987). While anchored by physical realities, we believe that contexts are fundamentally social realities (Searle 1995) that are constructed by people in interaction with each other (Ceci and Roazzi 1994; Goodwin and Duranti 1992; Gumperz 1982, 1992; Leander 2001; Tannen 1993; van Dijk 2008). Here we investigate the idea that otherwise physically similar contexts can be framed as quite different social realities that may encourage or discourage transfer (Engle 2006). As Pea (1987, p. 647) explained, "contexts [that matter for transfer] are not defined in terms of physical features of settings, but in terms of the meanings of these settings constructed by the people present."

We use the term framing to refer to the communicative processes of establishing these social realities (Bateson 1972; Goffman 1974; Goodwin and Duranti 1992; Hammer et al.

\footnotetext{
${ }^{1}$ By "context," we are referring to the physical and social contexts in which learning and transfer interactions occur. We are not using the term "context" to refer to "problem contexts," or the cover stories in which problems are sometimes embedded (Wagner 2006).
} 
2005; Tannen 1993). ${ }^{2}$ Contextual framing is usually initiated in social interactions through meta-communicative signals about the context itself (Gumperz 1982, 1992; Hammer et al. 2005; Tannen 1993). For example, through organizing the desks in a classroom in particular ways and making certain kinds of directives, a teacher can work to frame a classroom as one in which students learn by quietly listening or by collaboratively engaging in knowledge construction with each other.

For purposes of understanding transfer, we focus on different ways that the boundaries of learning and transfer contexts can be framed, as this framing affects which contexts students orient to as being relevant sites for using what they have learned. For example, a teacher can introduce a lesson as an opportunity for students to begin taking on knowledgeable roles within communities they plan to participate in throughout their lives. Doing so expands the social boundary of the lesson temporally, spatially, and socially to encompass additional times, locations, and people for which each student's understanding of the lesson will be relevant. In contrast, the same teacher could have introduced the same lesson as only relevant to the next day's quiz, framing it much more narrowly as divorced from other contexts. By making links between the classroom and other contexts, the teacher's first framing created what is referred to as "intercontextuality" between contexts while the second framing did not (Bloome et al. 2005; Floriani 1994; Gee and Green 1998; Leander 2001; Putney et al. 2000). The creation of intercontextuality is thought to give learners the message that they are allowed, encouraged, and even responsible for transferring what they know from one context to all others linked with it (Brown 1989; Engle 2006; Greeno et al. 1993; Pea 1987).

Here we investigate the specific hypothesis that transfer is more likely to occur when learning and transfer contexts are framed expansively ${ }^{3}$ as opportunities for students to actively contribute to larger conversations that extend across times, places, people, and activities (Engle 2006). The boundaries of expansive learning contexts are framed as being wide-ranging and permeable, increasing the number of contexts that can become intercontextually linked with them. Learners also become positioned as authors who share their knowledge, making them more likely to contribute what they know more generally (Greeno 2006). Thus, when an expansive framing is in effect, learners learn under the assumption that they will be expected to transfer what they have learned to other, future contexts (LCHC 1983; Pea 1987). They also make contributions in potential transfer contexts under the assumption that they are accountable for using what they learned from past places, times, and people (Bereiter 1995; Brown 1989; Campione and Brown 1984; Greeno et al. 1993; Pea 1987). Correspondingly, we predict that transfer will be discouraged to the extent that contexts are framed in a bounded manner, with constricted, impermeable, and non-overlapping boundaries. This occurs when contexts are narrowly

\footnotetext{
${ }^{2}$ The interactional process of framing should be distinguished from the notion of a "cognitive frame," which is a knowledge structure that may be cued in a particular situation and guide people's interpretations of and responses to it (Minsky 1975; Tannen and Wallet 1987), and can also affect the nature of transfer (Reed 1993; Wagner 2006). Creider (2009) provides a helpful discussion of the distinctions between these two notions, which she labels "interactive frames" and "cognitive frames," respectively.

3 We are replacing Engle (2006)'s term “ongoing activities" with "expansive" as it better captures the hypothesis, which goes beyond the framing of time to include other aspects of contexts. Our use of the term "expansive" may remind some readers of Engeström's (e.g. 2007) concept of "expansive learning," which is the process through which organizations surface underlying contradictions to create new forms of activity. Although a full discussion of the differences and potential resonances between these two uses of "expansive" goes beyond the scope of this article, our current understanding of Engestrom's work suggests that a collectively-realized form of expansive framing may help support expansive learning.
} 
defined as individual events within a single location involving a restricted set of participants and topics, and in which learners do not play such central intellectual roles.

Thus, the primary differences between expansive and bounded framings is in how wideranging and permeable their boundaries are, and whether they therefore include students inside them as key contributors to the activity.

\section{Existing empirical evidence about framing contexts and transfer}

Few studies have empirically investigated potential connections between framing contexts and transfer. Two classroom design-based research studies provide complementary evidence that transfer may be affected by framing while a recent experiment systematically tested one aspect of it. Hammer et al. (2005) showed that when two transfer contexts were re-framed as being about active student sense-making rather than simply the replication of knowledge, students were more likely to "transfer in" (Schwartz et al. 2005) their prior knowledge in ways that helped them understand physics concepts. Engle (2006) presented a case of successful transfer that occurred despite weak content-based supports and showed how it could be explained through a teacher's framing of the learning context. The teacher expansively framed her interactions with students by: (a) temporally connecting to prior and future interactions in which students could use what they were learning; and (b) positioning students as contributing to a larger community of people interested in what they were learning about. Engle (2006) argued that this framing may have encouraged the students to orient to their explanations as being applicable across contexts. Finally, Hart and Albarracin (2009, experiment 2) showed that people are more likely to repeat an action they have just engaged in - the most basic form of transfer that there is (cf. Salomon and Perkins 1989) - if they are prompted to describe it using a progressive verb aspect that frames it as a continuing activity ("I was doing....") versus a perfective aspect that frames it as a completed action (e.g., "I did...").

\section{A tutoring experiment to investigate the effects of framing on transfer}

The current study aims to incorporate the best of both kinds of prior studies on framing and transfer (see Engle et al. 2008 for details). Drawing on design-based research methods, we investigated framing and transfer within a complex learning ecology situated within a familiar educational activity (Cobb et al. 2003; Collins et al. 2004; Design-Based Research Collective 2003), namely one-on-one tutoring provided at a university (e.g., Chi et al. 2001; Cohen et al. 1982; Graesser et al. 1995; VanLehn et al. 2003; Wagner 2006) to high school students. Drawing on experimental methods, to identify potential causal effects we systematically manipulated framing while controlling for as many other instructional supports for transfer as possible (Shadish et al. 2002). Combining both traditions (Brown 1992; McCandliss et al. 2003), we iteratively designed and redesigned two systematically contrasting learning ecologies until they clearly embodied our developing theory's predictions about the kinds of framing that promote or discourage transfer. We then crystallized each design into a detailed protocol that specified what tutors were to say and do with every high school student in a given framing condition along with guidelines for consistently responding to questions, comments, and other events initiated by students.

We then used this documentation along with multiple measures of transfer and other relevant variables (Cobb et al. 2003; Collins et al. 2004; Design-Based Research Collective 2003; Shadish et al. 2002) to begin addressing the following research questions: 
1. Is it possible to systematically manipulate framing while controlling for other supports for transfer in a small-scale tutoring experiment?

2. If so, will the framing manipulation reliably affect students' propensity to transfer?

3. If so, what types of transfer are affected by framing?

Conducting a small-scale experiment that was informative about the effects of framing on transfer posed notable challenges. First, several investigators have claimed that transfer is rarely observed in laboratory settings (e.g., Detterman 1993; Lave 1988). ${ }^{4}$ To make it more likely that students would learn enough to make transfer possible (Bransford et al. 1999), we drew on established instructional methods and materials for supporting students' learning of the cardiovascular system (Chi et al. 1994, 2001). We then assessed transfer to the closely related respiratory system (Hmelo-Silver et al. 2007; Lui and Hmelo-Silver 2009). We also made moderate and consistent use of known methods for supporting transfer in an effort to avoid floor and ceiling effects. We then looked for the transfer of multiple kinds of knowledge (facts, principles, and strategies) and assessed them in multiple ways to maximize the chance of detecting any effects that may exist.

Second, we had the challenge of getting students to perceive and take up each contrasting framing of the tutoring sessions within a matter of minutes rather than the weeks in which the expansive framing was established in the classroom studied in Engle (2006). We addressed this challenge by manipulating the framing of multiple aspects of the tutoring contexts at once and to the strongest extent possible. We also continually maintained the framing throughout the entire study, which was aided by the one-on-one tutoring format (Aleven et al. 2006). We then measured how often the tutor manipulated each aspect of framing in the two protocols, and tracked students' responses to the tutor's framing moves, both in the moment and on a post-tutoring survey.

Third, there was the significant challenge of manipulating framing while holding constant numerous other instructional supports for transfer within a complex learning situation. We addressed this challenge in part by reducing the tutor's role as a provider of content by having all students self-explain (Chi 2000; Chi et al. 1994) the same set of instructional materials. At the same time, the points in the protocol where it was initially more difficult to control for other supports for transfer led to hypotheses about how framing may interact with these other mechanisms, an issue we return to in the discussion.

Thus, the contribution of this study is as much in its methods as it is in its findings.

\section{Method}

\section{Design}

The tutoring experiment had a $2 \times 2$ design with framing condition (expansive vs. bounded) as a randomized variable and student population (high school General Biology vs. high school Advanced Placement [AP] Biology students) as a fixed variable that was included to assess the generality of any effects across populations. Matched pairs of students from the same biology class who performed similarly poorly on a screening assessment consisting of a subset of the main transfer measure were randomly assigned to each framing condition to reduce pre-intervention differences between conditions and

\footnotetext{
${ }^{4}$ However, unlike most laboratory experiments, our setting was also one in which high school students were genuinely coming to be tutored, not just to participate in somebody's study (see Engle et al. 2008).
} 
increase experimental power (Shadish et al. 2002). Each student participated individually in a 3-4 h learning session about the cardiovascular system on 1 day followed by a $1-2 \mathrm{~h}$ transfer-of-learning session about the respiratory system the next day. Each session consisted of the following activities in order: instructions, pre-test, tutoring, survey, and posttest. All students were provided with four movie tickets to thank them for their participation.

\section{Participants and their originating biology classes}

A total of 24 students taking a biology course in the same Northern California high school participated in the experiment, 14 from General Biology and 10 from AP Biology, with half of each population assigned to each condition. Students were in grades 9-12 and ranged in age from 13 to 18 years old. The high school consisted of 38\% Asian, 36\% White, 12\% Latino, 9\% African-American, and 2\% Filipino or Pacific Islander students. About $15 \%$ of students in this school applied and were qualified to receive free or reduced price lunches (a standard measure of low socioeconomic status in the United States), which makes this population of students roughly middle-class by California standards. These figures are likely to be more representative of the General Biology classes from which we recruited as almost all students in the school take this course.

All selected participants had provided incorrect but readable and complete responses to the questions on the screening assessment. This ensured that they had not mastered the relevant content, but had sufficient motivation and language skills to fully participate in the study. No classroom instruction was provided about body systems during the few days or weeks between when a student completed the assessment and participated in the study.

Instruction in both biology courses was generally consistent with a bounded framing. In most lessons, students took notes from lectures, the textbook, and educational movies. Each student was evaluated primarily on his or her ability to correctly recall individual facts from these sources. The AP course did have some expansive framing in that it was intercontextually linked to the end-of-year AP exam and students' future college careers.

Similarities in procedures across all conditions and populations

We controlled for several elements of instruction that can affect learning and transfer, aiming in both conditions to strongly support learning while only moderately supporting transfer. Additionally, we controlled for the physical features of the contexts in which tutoring occurred.

\section{Content focus}

For all conditions and populations, the first day tutor's primary instructional goal was to have all students master the same facts and principles about the cardiovascular system whose transfer to the respiratory system would be assessed on day 2. For facts, students learned the sequence of body parts through which blood flows as they overlap with where oxygen travels within the respiratory system. This material is necessary for forming correct mental models of each system (Chi et al. 1994; Hmelo-Silver et al. 2007). For principles, students learned two fundamental macroscopic regularities that apply within and beyond body systems but are still learnable within a single session so their transfer could be investigated. Students learned that pressure differentials determine the direction of blood 
flow in the cardiovascular system, which then applies to gas movement in the respiratory system as well as fluid flow more generally (Michael et al. 2002; Yip 1998). They also learned that the large collective surface area of capillaries increases diffusion rates, which then applies to increasing the rates of diffusion across the alveoli in the respiratory system as well as the rates of many other physical and chemical processes (e.g., dissolving, heat transfer, chemical reactions; Odom and Barrow 1995, 2007).

\section{Tutoring methods}

The same tutoring methods were used across conditions and populations. The foundation of day 1's tutoring was having each student self-explain the same text about the cardiovascular system (adapted from Chi et al. 2001 to focus on the target facts and principles), a method shown to promote both learning and transfer (Chi 2000; Chi et al. 1994; RittleJohnson 2006). Drawing on methods established in prior research (Chi 2000; Chi et al. 1994; McNamara 2004), students were first trained to self-explain using an unrelated science text (Macaulay 1988), and then asked to read each sentence from the cardiovascular system text out loud and self-explain it. Although most students regularly selfexplained without difficulty, if the tutor observed a student only paraphrasing a sentence (cf. Hausmann and vanLehn 2007), she prompted for a more elaborate explanation.

Self-explaining of the text was supplemented with several instructional methods to further foster students' learning on day 1. First, students were provided with diagrams and were prompted to identify key body parts mentioned in the text. Second, at the end of each paragraph students were asked to answer focusing questions that asked about structures, behaviors, functions, and their relationships (Goel et al. 1996; Hmelo-Silver et al. 2007; Hmelo-Silver and Pfeffer 2004). When the text began detailing specific body parts, students were required to draw diagrams to represent their evolving models of the system (Ainsworth and Loizou 2003). For the target principles, students were asked pre-planned targeted questions about them and presented with a gestural or physical model for each. Finally, at the very end of the first day, the tutor confirmed that every student could successfully explain how both pressure and surface area are relevant to how the cardiovascular system works.

Tutoring about the respiratory system on day 2 was much less guided. Students were first asked to anticipate what they would need to learn about the respiratory system. They were then asked to "think aloud" while reviewing a text (adapted from Hmelo-Silver and Pfeffer 2004), hypermedia system (identical to those in Lui and Hmelo-Silver 2009), and diagrams for as long as they wished. They were also provided with pen and paper, but not required to use it, which provided an opportunity for them to spontaneously transfer the learning strategy of drawing diagrams from day 1 . The only two guided aspects of this tutoring session related to the target principles in that each student was asked to: (a) explain a classic lung model that uses a small soda bottle and balloons to represent pressure differentials, and (b) explain why there are so many alveoli in our lungs, which relates to the surface area principle.

\section{Instructional support for transfer}

There were no differences between conditions in the tutors' or instructional materials' embodiment (or lack thereof) of the following potential instructional supports for transfer: (a) direct hints (e.g., Anolli et al. 2001; Gick and Holyoak 1980; there were none), (b) references to the respiratory system prior to day 2 (again none), (c) overlapping surface 
linguistic cues between learning and transfer contexts (e.g., Catrambone 1998; same three cues), (d) examples provided of each principle (e.g. Gick and Holyoak 1983), (e) comparisons between those examples (e.g. Gentner et al. 2003), and (f) level of abstraction of statements of each principle (e.g., Reeves and Weisberg 1994). However, to maximize the chance of detecting an effect for at least one of the principles, we provided different degrees of content-based support for each one. Three examples and two comparisons were provided for the differential pressure principle while one example and no comparisons were provided for the surface area principle.

\section{People present with the student}

Controlling for one aspect of the physical context, all students interacted with different people on each day of the study. On the first day, the tutor was always the first author and the videographer was a research assistant. On the second day, the tutor and videographer were different research assistants. Although non-present members of the research team were often referred to in the expansive condition (see "Operationalization of Framing Manipulation" below), no student actually saw any of the same people on both days.

\section{Physical location of study}

Both days of the study occurred in the same laboratory room, but the student, tutor, and videographer were located in different places within it on each day in ways that were identical across conditions and populations. This controlled for a second key aspect of the physical contexts of the study.

Operationalization of the framing manipulation

We manipulated the framing of five key aspects of the tutoring contexts: when, where, who, what, and how (Engle 2006, building on Hymes 1972). Here we provide brief examples of each framing in classrooms and then in our tutoring experiment, with each sentence presenting the more bounded framings first and the more expansive ones second:

- When is the activity happening? The temporal horizon of a lesson can be framed as an isolated event that has been completed or part of an ongoing activity that will be continuing (analyzed in Engle 2006 and Leander 2001; discussed in Lemke 2001; partially manipulated in Hart and Albarracin 2009). In our experiment, we framed each day as separate studies that themselves consisted of separate completed sub-events versus as one ongoing study that extended across the 2 days and beyond to particular times students mentioned as being relevant to what they were learning.

- Where is it happening? Lessons can be framed as only being relevant to the particular classroom or as also being relevant to other places like the rest of the school, the local community, a profession, the country, the world, etc. (proposed in Barnett and Ceci 2002; analyzed in Leander 2001). In our experiment, we framed the study as being contained to the room versus happening at the university where the tutoring was taking place as well as being relevant anywhere else students mentioned.

- Who is participating in it? Lessons can be framed as just involving the teacher with each individual student separately, or as being relevant to a much larger community in the classroom and beyond (analyzed in Engle 2006). In the tutoring experiment, we 
framed the student as interacting separately with each tutor versus collectively with the whole research team and anyone else students mentioned when queried.

- What is the topical scope of the activity? Two lessons can be framed as being relevant to separate classes, curriculum units, or topics, or as being part of the same larger subject area, unit or topic (proposed in Pea 1987). In our experiment, we introduced each 1-day study as being about either the cardiovascular or the respiratory system versus the whole 2-day study as being about body systems. ${ }^{5}$

- How are learners positioned intellectually? In lessons, learners can be framed as disconnected recipients reporting about the ideas of others or as authors and respondents who are developing and taking responsibility for their own ideas (analyzed in Engle 2006 and Hammer et al. 2005; discussed in Greeno 2006). In our experiment, we framed the learner as a recipient of and spokesperson for the text versus as the author of his or her own ideas who responded to the text.

The first three bullet points ("when," "where" and "who") collectively represent how the setting of learning and transfer contexts is framed while the last two represent the framing of topic ("what") and intellectual roles ("how").

Specifics about how these contrasts were embodied in the tutor's language and actions appear in Table 1. Students usually implicitly accepted the tutor's proposed framings by neither objecting to them nor proposing alternatives. This is not surprising given that the tutor was simultaneously the experimenter whose instructions students had tacitly agreed to follow and an instructor who is generally expected to direct student activities (Pace and Hemmings 2007). Whenever alternative framings were presented, the tutor consistently encouraged the favored framing and discouraged the alternative until student uptake was achieved. For example, some students in the expansive condition initially attributed authorship to the text by presenting their self-explanations as being about what the "text said." To disrupt this undesirable bounded framing, the tutor asked the student whether he or she agreed with those ideas and then made a point of revoicing (O'Connor and Michaels 1996) the agreed-upon ideas as the student's. The tutor would continue to encourage the student to share his or her own ideas until the student was regularly prefacing his or her self-explanations with phrases like "I think" or "I know."

In order to maintain the different framings of students' roles, the tutor needed to use slightly different tactics to encourage students to revise their knowledge when they were confused about something. In neither condition could the tutor directly tell the student the correct knowledge as this would take authorship away from the student (expansive condition) or the text (bounded condition). Instead, the tutor first asked the student to elaborate further either on their idea (expansive) or that of the text (bounded), which often prompted the student to identify the difficulty and begin resolving it. If not, the tutor would point out something inconsistent or vague that could be attributed as being from the students' prior self-explanations (expansive) or another part of the text (bounded), and then ask the student how it related to what they'd been thinking (expansive) or reporting (bounded) about.

\footnotetext{
5 We recognize that there is a family resemblance between this manipulation and the content-based mechanism of abstraction, an issue we will address in the discussion.
} 
Table 1 Operationalization of framing manipulations in the tutoring experiment

Aspects of contexts that can be framed

\section{Expansive Framing}

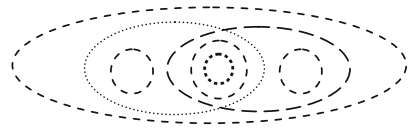

(Predicted to Promote Transfer)

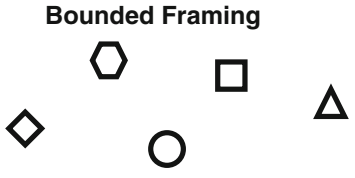

(Predicted to Discourage Transfer)
A. Setting

1. Time

2. Place

3. Participants

B. Topic

C. Role

1. Instructed

2. Positioned
Ask student to specify other settings in which the topic(s) have, are, or will be likely to come up in their lives

a. Refer to both days together as comprising a single study

b. Refer to other times, both inside and outside of the experiment

c. Use present progressive verbs (“you're continuing to do that")

a. Frame location as "the university"

b. Refer to other places they said they'd use what they're learning

a. Treat larger activity as involving the student, the whole study team, and anyone else they mentioned

b. Ask student to imagine explaining their ideas to other people

Whole study about "body systems," with "circulatory" one of them. "Respiratory system" not called a "body system"

Author of ideas and respondent to text:

Student asked to explain their own evolving ideas about the system using the text as a resource

Revoice student's self-explanations, crediting student with authorship and checking whether reformulation is accurate
Do not ask student to specify other settings in which the topic has, is, or will be likely to come up in their lives

a. Refer to each day as a separate study including separate events

b. Make no references to times other than the just completed present

c. Use simple past perfective ("you're now done with that")

a. Frame location as "this room"

b. Make no references to other places

a. Treat tutoring event as a private matter involving only you and the student-no one else

b. Only have student explain the text's ideas to you or themselves

Each day either about the "circulatory system" or the "respiratory system"

Spokesperson \& recipient of text' ideas:

Student asked to use own words to explain the text's ideas about the system in each sentence

Credit students self-explanations as what the text has presented to them

\section{Instruments}

Below we describe: (1) a post-tutoring survey; (2) a pre/post test about the cardiovascular system; and (3) an analogous pre/post test about the respiratory system that served as the primary transfer assessment and source for the screening test.

\section{Post-tutoring survey}

To measure the degree to which students detected the intended framing of their sessions and their general level of motivation during tutoring, the videographer asked each student to complete a survey during a break immediately after tutoring. The tutor was out of the room and instructions were designed to reduce any student efforts to please the tutor or 
videographer through their responses. Eight-seven-level Likert-style questions in the survey sought to measure students' perceptions of different aspects of the framing manipulation. For example, "How often did you notice the tutor emphasizing the importance of past and present situations during the session?" was used to measure students' perceptions of the framing of time. A ninth question "How much did you care about learning about the cardiovascular/respiratory system" ( $1=$ not very much, $7=$ a lot $)$ was included to provide a basic measure of each student's degree of motivation, which may also contribute to transfer (Pugh and Bergin 2006).

\section{Cardiovascular system pre/post test}

At the beginning and end of day 1's tutoring session, a written pre/post test (adapted from questions used by Chi et al. 1994, 2001) measured students' knowledge of the target facts and principles about the cardiovascular system that could be applied to the respiratory system (see left column of Table 2).

\section{Respiratory system pre/post test}

To measure transfer we devised analogous written assessment questions about the respiratory system (right column of Table 2) whose wording paralleled those used in the cardiovascular assessment in the tradition of classic transfer experiments like Gick and Holyoak (1980). To partially counteract this similar surface cue, the two assessments used different typefaces (Spencer and Weisberg 1986). The fact question and the first question about each principle comprised the three-item screening test that was used to select students to participate in the study.

Table 2 Paired questions used for assessing learning and transfer for the two body systems

\begin{tabular}{|c|c|}
\hline Cardiovascular system & Respiratory system \\
\hline \multicolumn{2}{|l|}{ Facts } \\
\hline $\begin{array}{l}\text { Starting in the heart, please list in order every part } \\
\text { of the body that you think blood travels through as } \\
\text { it moves through the cardiovascular system. }\end{array}$ & $\begin{array}{l}\text { Please list in order every part of the body that you } \\
\text { think oxygen travels through as it travels from } \\
\text { outside your body to your body's cells. }\end{array}$ \\
\hline \multicolumn{2}{|l|}{ Differential pressure principle } \\
\hline $\begin{array}{l}\text { a. As the blood flows from the atrium to the } \\
\text { ventricle, what do you think the fluid pressure is } \\
\text { like inside the left atrium as compared to inside the } \\
\text { left ventricle? }\end{array}$ & $\begin{array}{l}\text { a. As a person is breathing out, what do you think } \\
\text { the air pressure is like inside the lungs as compared } \\
\text { to outside the body? }\end{array}$ \\
\hline $\begin{array}{l}\text { b. In your opinion, what causes blood to flow from } \\
\text { the lungs to the left atrium? }\end{array}$ & $\begin{array}{l}\text { b. In your opinion, what causes air to flow from the } \\
\text { trachea (or windpipe) into the lungs? }\end{array}$ \\
\hline \multicolumn{2}{|l|}{ Surface area principle } \\
\hline $\begin{array}{l}\text { a. What, if anything, do you think would happen if } \\
\text { the many small capillaries were replaced by a few } \\
\text { big blood vessels that still held the same volume of } \\
\text { blood? }\end{array}$ & $\begin{array}{l}\text { a. What, if anything, do you think would happen if } \\
\text { the many small alveoli (or air sacs) in the lungs } \\
\text { were replaced by a few big alveoli that still held the } \\
\text { same volume of gas? }\end{array}$ \\
\hline $\begin{array}{l}\text { b. Considering that so many things (ex: gas, } \\
\text { nutrients, waste) must go through capillary walls, } \\
\text { what do you think are at least two characteristics } \\
\text { these walls probably have? }\end{array}$ & $\begin{array}{l}\text { b. Considering that so much gas must go through the } \\
\text { membranes (or walls) of alveoli in the lungs, what } \\
\text { do you think are at least two characteristics these } \\
\text { membranes probably have? }\end{array}$ \\
\hline
\end{tabular}


Analytical methods

\section{Coding}

All coding was done blind to condition and not by the first author. If any interpretation was involved, the coding was reliably performed by two coders on a random sample of at least $25 \%$ of the data, with any differences resolved through discussion. We coded assessments at all five time points-screening, pre-cardiovascular, post-cardiovascular, pre-respiratory, and post-respiratory. More straightforward measures included timing the length of tutoring sessions, identifying the relevant parts of the body listed in response to question one, and determining whether or not each student had drawn a diagram during the second day's tutoring.

To code for the transfer of facts, we examined student responses to the first question on each corresponding assessment (see top row of Table 2). The ten parts of the body that oxygenated blood passes through (lungs, lung's capillaries, veins, left atrium, mitral valve, left ventricle, aortic valve, aorta, arteries, body's capillaries) are the same as the parts of the body that oxygen passes through between the lungs and the body's cells. Therefore, we assessed transfer of facts by simply counting the number of these common facts included in students' responses to each assessment and comparing them.

To code for the transfer of conceptual principles, we also identified and compared individual knowledge elements. To do so, we divided each principle into a set of individual propositions (Renkema 2004; van Dijk and Kintsch 1983) that could be included by students in their responses to each pair of analogous questions (see bottom four rows of Table 2) at each assessment time point. Together each set of two pairs of questions for each principle provided 12 codeable propositions relevant to differential pressure and 11 codeable propositions relevant to the surface area $(91 \%$ agreement; Kappa $=.82)$. A list of the propositions assessed per question pair appears in the Appendix.

Our coding for transfer of the learning strategy of diagram drawing was much more straightforward. We only needed to record which students did and did not chose to draw diagrams during the tutoring session on day 2. Recall that all students had been required to draw diagrams during tutoring on day 1 , but could decide whether or not to do so on day 2 after being provided with pen and paper.

\section{Transfer measures}

In order to assess immediate transfer of facts and conceptual principles, we employed three different but partially overlapping measures, which for purposes of this paper are labeled "transfer-of-learning," "transfer-of-knowing," and "transfer-after-exposure" (see Table 3). Transfer-of-knowing occurs when a student can be shown to apply something to one system that he or she can be shown to have already known with a related system. It was measured by calculating the proportion of material (i.e., facts or propositions) included in either or both of a given student's cardiovascular tests that re-appeared in his or her respiratory system pre-test. Transfer-of-learning occurs when a student can be shown to have applied something to a new system that he or she can be shown to have learned earlier with a different but related system. It was measured by calculating the proportion of material that appeared in each student's cardiovascular system post-test but not his or her pre-test that then re-appeared in his or her respiratory system pre-test. Finally, transferafter-exposure occurs when a student can be shown to increase the extent to which they use a set of ideas with one system after being exposed to those same ideas with another related 
Table 3 Equations and focus of transfer measures used for facts and principles

\begin{tabular}{|c|c|c|}
\hline Measure & Focus & Equation \\
\hline Transfer-of-knowing & $\begin{array}{l}\text { Knowledge moving between } \\
\text { systems }\end{array}$ & $\frac{\text { In Respiratory Pre and (Cardio. Pre or Cardio. Post) }}{\text { In Cardio. Pre or Cardio. Post }} \times 100 \%$ \\
\hline Transfer-of-learning & $\begin{array}{l}\text { Learning moving between } \\
\text { systems }\end{array}$ & $\frac{\text { In (Resp. Pre and Cardio. Post) but Not Cardio. Pre }}{\text { In Cardio. Post but Not Cardio. Pre }} \times 100 \%$ \\
\hline Transfer-after-exposure & $\begin{array}{l}\text { Change in same test after } \\
\text { exposure }\end{array}$ & $\frac{\text { In Respiratory Pre but Not Respiratory Screening }}{\text { Not in Respiratory Screening }} \times 100 \%$ \\
\hline $\begin{array}{l}\text { Preparation-for-future- } \\
\text { learning }\end{array}$ & $\begin{array}{l}\text { Prior learning aids new } \\
\text { learning }\end{array}$ & $\frac{\text { In (Resp. \& Cardio. Post's) but Not (Resp. or Cardio. Pre's) }}{\text { In Cardio. Post but Not (Resp. or Cardio. Pre's) }} \times 100 \%$ \\
\hline
\end{tabular}

system (a version of the measure used by the classic Thorndike and Woodworth 1901 study). It was measured by calculating the proportion of facts or propositions a student did not show evidence of knowing in the respiratory screening test that he or she included in the same parts of the respiratory pre-test. This measure complements the others by controlling for students' prior knowledge about the respiratory system. Although in all cases students are in fact transferring what they have learned somewhere, only the transfer-oflearning measure allows us to definitively say that the transferred material was learned during the experiment itself. The purpose of using these three different but related measures was to determine the degree to which they would provide converging evidence for any transfer effects, and whether effects of framing on transfer are more likely to show up on one measure than another as that could be theoretically significant for understanding how framing works.

If insufficient immediate transfer was observed to be able to detect any effects between groups, we measured preparation-for-future learning transfer (Bransford and Schwartz 1999; Schwartz et al. 2005), which is when prior learning facilitates future learning. Within this perspective, prior learning may increase the quality, efficiency or amount of future learning. Here we focus on amount by calculating the proportion of related material that a student learned about the respiratory system on day 2 after having learned similar material from the cardiovascular system session on day 1 .

\section{Statistical methods}

Unless otherwise stated, two-tailed independent sample $2 \times 2$ ANOVAs were used to detect interactions and main effects due to condition (expansive vs. bounded) and population (AP biology vs. general biology) for all quantitative outcome variables. Whenever interactions were detected, Tukey's (1953) honestly significantly different (HSD) procedure was used to determine which pairs of cell means were significantly different from each other. Correspondingly, a 3-way log linear analysis was used for the one categorical outcome variable (whether each student drew a diagram).

As implied above, our primary method for aggregating our data was by student rather than by assessment items or individual knowledge elements (i.e. facts or propositions). We used this method because the hypothesis being tested is that framing affects each student's overall propensity to transfer irrespective of the particular pieces of knowledge that are involved. There is no particular reason to believe that framing a learning context will differentially affect students' propensity to transfer some knowledge elements more so than others. In addition, it turned out that aggregating by students led to fewer problematic 
proportions with zero denominators than aggregating by knowledge elements as there were far fewer floor and ceiling effects in learning and transfer by particular students than for particular knowledge elements.

\section{Results}

We begin by assessing the degree to which students perceived the intended differences in framing. We then examine whether groups differed in basic factors that could affect transfer, like prior knowledge, interest in the topics, time-on-task, and amount of learning. Finally we present the main findings about whether the framing manipulation influenced students' propensity to transfer the facts, principles, and learning strategy.

Did students perceive the framing manipulation?

Evidence from day 1's survey indicates that students generally perceived the intended differences in framing by condition, with the framing of roles and time being the most salient to them. We put each student's responses to the eight survey questions about their perceptions of framing together to create an expansive framing score, and used a $2 \times 2$ ANOVA to compare mean scores by condition and population. There was a large main effect $(d=1.4)$ of condition, with students in the expansive condition scoring a mean of $39.4(S D=3.1)$ and those in the bounded condition scoring a mean of $32.4(S D=6.4$; $F(1,19)=10.6 ; p=.004)$. There was no interaction effect or main effect of population.

The effect was supported by significant main effects of condition for questions focusing on the framing of roles and time, which makes sense given that the tutor had more frequent opportunities to frame those two aspects of the tutoring context than the others. Although these findings should not be over-interpreted given this is a new survey, the fact that statistically reliable effects between conditions were found is consistent with a successful manipulation of framing.

Were there group differences in other factors affecting transfer?

We already know that all physical features of the tutoring contexts were the same for all groups and that the same instructional materials and overall tutoring methods were used. In this section, we look to see if there were any obvious differences between groups in several other factors that can affect transfer.

\section{No group differences in prior knowledge, time-on-task, and interest}

Three basic factors affecting learning and therefore transfer were equivalent across all groups. First, there were no statistically reliable differences between groups in students' prior knowledge as measured by the initial screening assessment $(M=15.4 \%$; $S D=5.8 \%$ ). Second, there were no differences in the time students spent learning about the cardiovascular system $(M=73.5 \mathrm{~min} ; S D=20.3 \mathrm{~min})$. Finally, on the post-tutoring survey, students in all groups reported caring about learning the cardiovascular system on day 1 and then the respiratory system on day 2 to similarly mild, positive degrees (cardiovascular system $M=5.4$ out of $7, S D=1.3$; respiratory system $M=5.2$ out of 7 , $S D=1.4)$. 


\section{No main effects by condition in amount of student learning}

There were no main effects by condition in amount of learning for any of the facts or either principle about the cardiovascular system whose transfer we measured. Students in both the bounded and expansive conditions learned a mean of 3.5 propositions about surface area $(S D=2.4), 3.4$ propositions about differential pressure $(S D=2.2)$, and 3.4 facts about the body parts shared by both systems $(S D=1.7)$. However, AP students learned almost twice as many propositions about the surface area principle $(M=4.9)$ than general biology students $(M=2.5 ; F(1,20)=7.67, p=.01)$. No other interaction or population effects on the amount of learning were detected. Given the wide individual variability in learning and the differences between AP and General Biology students with the surface area principle, it was helpful that our transfer measures all considered the proportions of potential material that were transferred rather than absolute amounts (cf. Schegloff 1993).

Differences by condition in students' propensity to transfer facts

With respect to transfer-of-knowing, there was a large main effect of condition (see Fig. 1; error bars represent standard errors here and throughout), with students in the expansive condition transferring $42 \%$ of facts they knew while those in the bounded condition only transferred $21 \%$ of them $(d=.89 ; F(1,20)=4.37, p=.04)$. Although the observed means appear lower for AP biology students, there were no statistically reliable differences between populations $(F(1,20)=2.82, p=.11)$ nor any interaction effects $(F(1,20)=0, p=1)$.

With respect to transfer-after-exposure, there was also a large main effect of condition $(d=.94)$, with students in the expansive condition listing $20 \%$ more facts than they had during the original screening assessment while students in the bounded condition listed 3\% more facts than they had originally $(F(1,19)=4.82, p=.04$; see Fig. 2). Again, there were no interaction effects $(F(1,19)=.28, p=.60)$ or main effects of population $(F(1,19)=0, p=1)$. Finally, with respect to transfer-of-learning, there was a trend in the direction of more transfer by students in the expansive (36\%) versus bounded $(13 \%)$ conditions $(F(1,20)=3.27, p=.09)$, with no other potential effects found (population: $F(1,20)=.2, p=.66$; interaction: $F(1,20)=.1, p=.76)$. Thus, on two of three ways of measuring transfer, transfer-of-knowing and transfer-after-exposure, there were large main effects of framing on the transfer of facts.

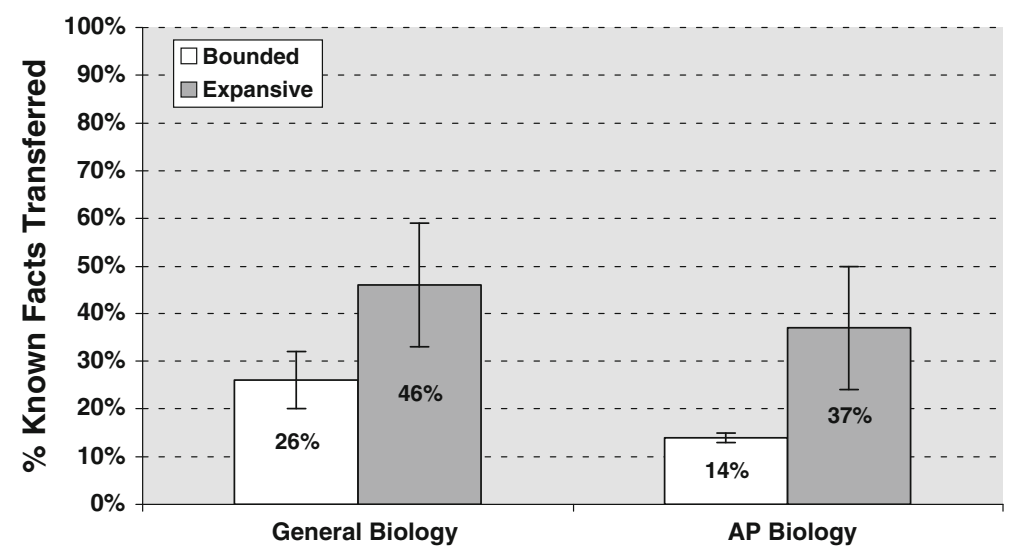

Fig. 1 Greater $\%$ transfer-of-knowing for facts in the expansive condition 


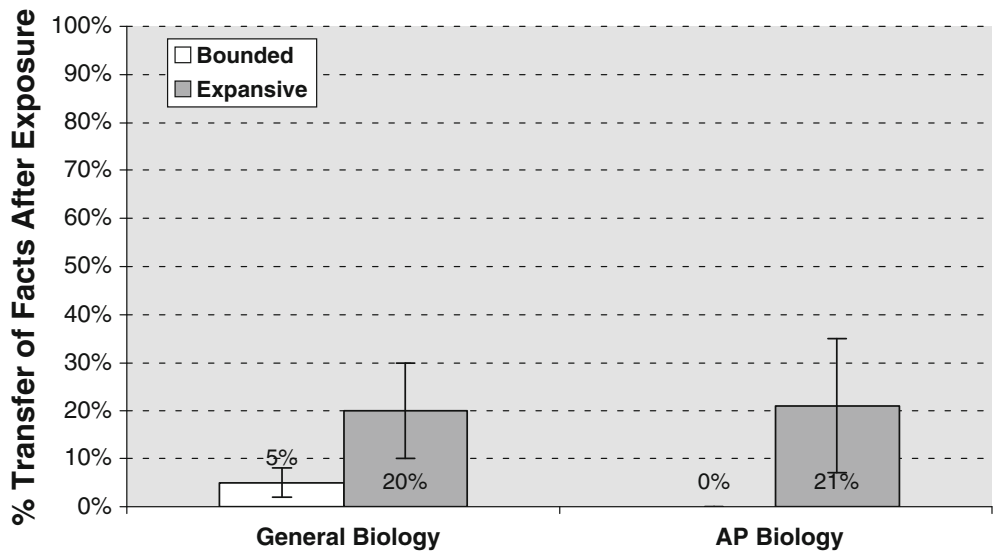

Fig. 2 Greater \% transfer-after-exposure for facts in the expansive condition

Partial evidence for differences by condition in the transfer of principles

For the differential pressure principle, there was a large main effect $(d=.95)$ of condition on transfer-of-knowing $(F(1,20)=5.42 p=.03)$, with no statistically reliable main effect of population $(F(1,20)=.34, p=.23)$ or interaction effect $(F(1,20)=1.53, p=.57)$ despite appearances (see Fig. 3). Students in the expansive condition transferred much $(M=78 \%)$ of what they knew while those in the bounded condition transferred only about half $(M=55 \%)$.

For transfer-of-learning, we conducted $t$-tests only using the data from the general biology students as insufficient numbers of AP biology students learned any new propositions about differential pressure. General biology students in the expansive condition transferred $78.6 \%$ of what they learned during the cardiovascular session while those in the bounded condition only transferred $33.6 \%$ of it (see Fig. $4 ; d=1.2 ; t(12)=2.27$, $p<.05)$. However, there were no differences between groups in transfer-after-exposure

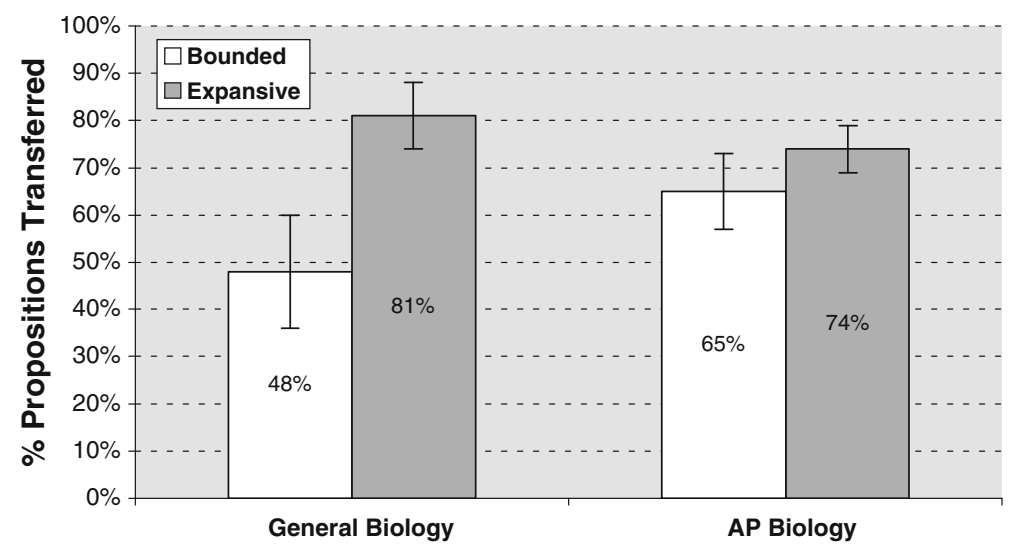

Fig. 3 Greater $\%$ transfer-of-knowing for the differential pressure principle in the expansive condition 


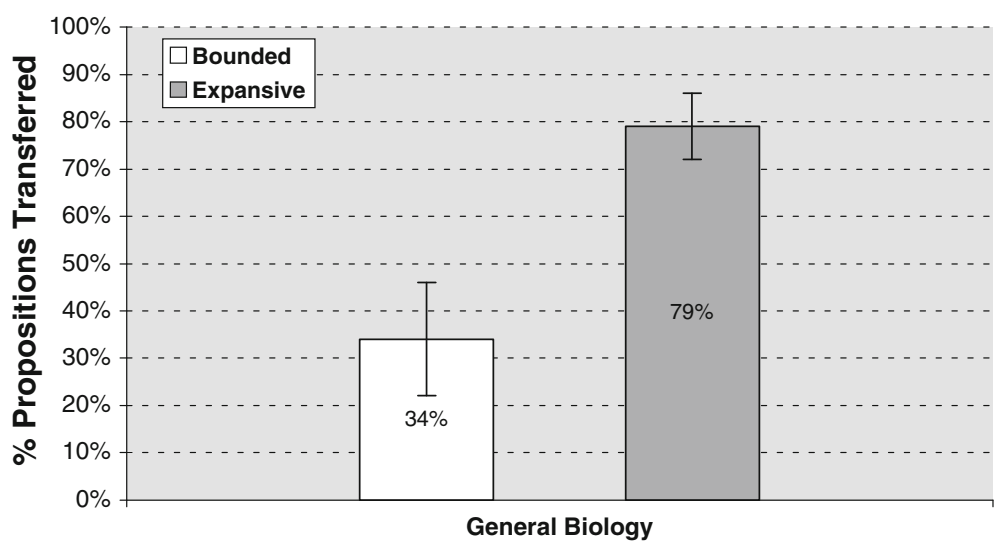

Fig. 4 Greater $\%$ transfer-of-learning for the differential pressure principle by General Biology students in the expansive condition

(all $p$-values $>.30$ ). Thus, overall, we saw statistically reliable effects of framing for two of the three measures of transfer for the general biology students.

For the surface area principle there were no main or interaction effects on immediate transfer when measured in each of the three ways, with $p$-values ranging from .12 to 1.0. Although the observed means favored the expansive $(M=71 \%, S D=27 \%)$ over the bounded $(M=59 \%, S D=37 \%)$ condition with the transfer-of-knowing measure, there was too much variability for any effects to be detected with this measure or for transferafter-exposure. Insufficient learning by enough students made the transfer-of-learning measure unmeaningful, so we checked for preparation-for-future-learning transfer. There were no effects of condition, although AP students showed significantly stronger rates of re-learning this principle for the respiratory system $(M=88 \%, S D=18 \%)$ than General Biology students $(M=31 \% ; S D=46 \%)$ despite scant data $(F(1,9)=5.68, p=.04)$. Thus, there is no evidence that framing condition affected students' propensity to transfer what they knew or learned about the surface area principle.

Differences by condition in transfer of the learning strategy of drawing diagrams

On the basis of a $2 \times 2 \times 2$ loglinear analysis, students in the expansive condition were much more likely to draw diagrams than those in the bounded condition $\left(G^{2}(2)=8.28\right.$, $p=.02$ ). Only 1 of the 12 students in the bounded condition drew diagrams while 7 of the 12 students in the expansive condition did so (see Fig. 5). There was also a trend in the direction of this effect being greater for General Biology than AP Biology students $\left(G^{2}(4)=8.52, p=.07\right)$.

\section{Discussion}

Summary of findings

We begin by returning to our research questions: 


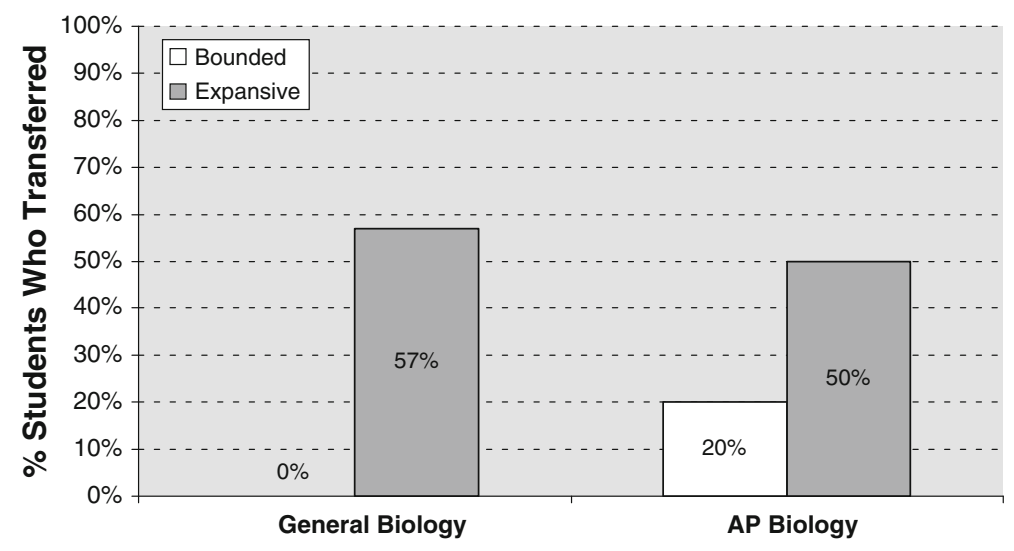

Fig. 5 Greater $\%$ transfer of the practice of drawing diagrams in the expansive condition

1. Is it possible to systematically manipulate framing while controlling for other supports for transfer in a small-scale tutoring experiment?

2. If so, will the framing manipulation reliably affect students' propensity to transfer?

3. If so, what types of transfer are affected by framing?

First, despite the challenges that were involved, we were able to design a small-scale experiment to investigate framing and transfer. We successfully manipulated framing as expansive versus bounded in ways that were perceived by students and that made the notions of expansive versus bounded framing much more concrete. This further specifies our evolving theory of framing and transfer (Engle et al. 2008) while providing initial guidance for educators to implement these contrasting framings. We also were able to control or keep equivalent between groups many other known supports for transfer including prior knowledge, time on task, interest, amount of learning, number of examples, use of labels, the degree to which examples were compared with each other, and the physical features of the contexts in which the study occurred. Thus, this study represents a good start at creating an experimental paradigm to identify what framing contributes to transfer over and above other factors. Finally, although not perfect, our instructional methods for supporting student learning were generally sufficient to detect effects of framing on transfer.

With respect to the effects of framing on transfer (research questions 2 and 3), we specifically found that students in the expansive condition were more likely than those in the bounded condition to transfer: (a) the learning strategy of drawing diagrams; (b) facts they knew or (c) had been exposed to; and (d) what they knew about the differential pressure principle. In addition, (e) general biology students in the expansive condition were more likely to transfer what they had learned about the differential pressure principle than those in the bounded condition. However, no statistically reliable differences were detected across conditions in any kind of transfer of the surface area principle, or in transfer-afterexposure for the differential pressure principle.

The fact that several large effects of framing on transfer were found within an otherwise small-scale experiment suggests that it likely that framing does play an important role in transfer. Although it is possible that some of the observed effects were a coincidence given the small sample size, the overall pattern of results suggests this is less likely. 
Framing also does not appear overly specialized in terms of what kinds of transfer it can influence. Here we saw the transfer of three different kinds of knowledge (facts, principles, and strategies) being affected by framing. This complements prior research showing that framing may affect the transfer of a method of explaining (Engle 2006) and repetition of an action (Hart and Albarracin 2009). Also, the fact that transfer-of-knowing effects occurred most consistently suggests that framing may influence students' propensity to transfer whatever it is they knew and contributed as opposed to only what they recently learned (as would be the case had the transfer-of-learning measure shown the strongest and most consistent effects).

It is also interesting to note that the effects of framing on transfer were generally stronger for General Biology students than AP Biology students. Although this may be due to content-based advantages for AP students, the idea that AP courses are generally framed more expansively also provides an additional, intriguing explanation to consider. In any case, it is encouraging that framing appears to have had greater effects on transfer for the less sophisticated student population.

\section{Implications for research}

It is not necessarily the case that all aspects of expansive framing have to be in place to see effects on transfer, however. In future research it will be important to investigate the effects of framing particular aspects of contexts alone versus in various combinations with one another. For example, is the role manipulation, which positions students as authors who regularly share their knowledge or recipients who have no such responsibilities, the most important for transfer (Greeno 2006)? Or maybe what really matters the most is the degree to which time and other aspects of settings are framed as being intercontextually linked with each other (Leander 2001). If more than one aspect of expansive framing matters, does each one make its own independent contributions or is the whole greater than the sum of its parts?

It also may be the case that different aspects of framing promote transfer in different ways. For example, building on Barnett and Ceci's (2002) helpful taxonomy of different kinds and degrees of near and far transfer, it easily may be that framing time expansively is especially helpful for promoting transfer over the course of years, framing location expansively is especially helpful when one if looking for transfer across settings like between school and home or work, and framing participants expansively is especially helpful for supporting transfer across different social groupings. More speculatively, we wonder whether being positioned as an author is especially helpful for transfer that involves greater cognitive demands (i.e., recalling, recognizing and executing something rather than simply executing it) and more sophisticated performances (engaging in an overall approach rather than simply providing a correct answer quickly).

To address these questions, future experiments can manipulate each aspect of framing alone and in coordination. This will simultaneously advance understanding of how exactly framing works, provide additional replication of the effects of framing on transfer, and guide educators about which aspects of framing to focus on.

The current experiment also opens up issues about how framing may interact with other instructional methods for supporting transfer. For example, the fact that framing did not affect rates of transfer of the surface area principle but did so for the differential pressure 
principle could be interpreted to suggest that framing's effects on transfer may be found only when there is at least some minimal level of content-based support for transfer, here through providing sufficient examples and comparisons between them. However, this finding may have occurred for other reasons specific to the nature of the specific content being learned (e.g., the surface area principle is arguably more mathematically complex than the differential pressure principle). More systematic comparisons would be needed in follow-up experiments to determine the degree to which the effects of framing on transfer may actually depend on sufficient content-based supports.

More generally it is possible that the framing of learning contexts in an expansive manner makes it more likely that students will learn under the assumption that they will need to transfer what they have learned in the future (Bereiter 1995; Brown 1989), which may prompt them to make better use of those content-based supports for transfer that are available to them (Engle 2006). For instance, students learning with an expansive framing may be more likely to bring in multiple examples from a wider range of contexts. They may also be more likely to make systematic comparisons between multiple examples to form generalizations in anticipation of applying what they have learned in the future (Salomon and Perkins 1989). Knowing that what they are learning will continue being relevant, learners may put more effort into becoming sensitive to the specific features of examples that make them suitable for applying relevant generalizations in particular ways (Wagner 2006). Although tracking exactly which examples, features, comparisons, and generalizations students generated and considered was beyond the scope of this study, it would be a compelling focus of future investigation.

We also think that there are some important resonances between the notion of expansive framing and prior research that has shown the strong power of hints for facilitating transfer (Anolli et al. 2001; Campione and Brown 1984; Catrambone and Holyoak 1989; Gick and Holyoak 1980, 1983; Spencer and Weisberg 1986). Although in our expansive framing we were careful to never provide the kinds of content-specific, and precisely timed hints that were investigated in these studies, expansive framing has a family resemblance with such hints by encouraging students to orient to what they know as being of continued relevance across times, places, people and topics.

In a similar way, there may be a family resemblance between framing topics expansively and the content-based transfer mechanism of providing sufficiently abstract generalizations (Catrambone and Holyoak 1989; Gick and Holyoak 1983; Mestre 2003). Although we purposely did not provide any abstract generalizations of the pressure or surface area principles in either condition, our use of the general term "body systems" to introduce the overall topic of tutoring on day 1 in the expansive condition may have oriented these students to view their activities as having more general relevance (Engle 2006; Greeno et al. 1993; LCHC 1983; cf. Shulman 1992). Although no students were told that what they were learning would apply to the respiratory system, the use of the term body systems may have opened up the possibility that facts, principles, and strategies relevant for understanding the cardiovascular system may apply to other body systems as well (cf. Murphy 2002).

\section{Implications for practice}

What is potentially so powerful about expansive framing is that it relies less heavily on teachers possessing particular kinds of content knowledge as compared to most other instructional supports for transfer. As a result, expansive framing may be easier for more 
teachers to implement across a wider range of subject areas and types of curricular materials. Additionally, if students come to regularly orient to learning activities in an expansive fashion (cf. Bereiter 1995; Brown 1989), then one would expect them to make greater use of prior knowledge more generally as they become increasingly accountable for sharing what they know across connected contexts. In contrast, the bounded framing discourages transfer both by binding knowledge to a particular instructional context and by keeping learners as disconnected from it as possible.

At the same time, however, we do not claim that expansive framing is the be-all or end-all for instruction. Our informal observations of the tutoring sessions and broader theoretical considerations suggest that there may be costs as well as benefits of expansive framing for both learning and transfer. For example, we observed that a few students in the expansive framing condition had a tendency to bring in so much prior knowledge while self-explaining that they became overwhelmed or had difficulty focusing on what the text could contribute to their understanding. Thus, it may make sense for the beginnings and endings of lessons or curriculum units to be framed more expansively, but to use a less expansive framing when students need to focus on learning important new material.

In addition, by itself expansive framing encourages students to regularly use what they already know, but it does not provide resources for students to judge which prior knowledge is the most appropriate for a particular problem or issue, which can lead to overgeneralization (Engle 2006). Therefore expansive framing should be regularly paired with activities in which students critically evaluate the knowledge they have transferred in for its relevance and validity. Nonetheless, it has long been recognized that the key challenge is in students being reminded of and transferring in their knowledge in the first place (e.g., Loewenstein 2010; Reeves and Weisberg 1994; Ross 1984), which is where framing becomes particularly relevant.

\section{Conclusion}

In closing, this study provides new empirical evidence that converges with prior experimental and classroom studies to show that framing of learning contexts is an important instructional mechanism to consider when trying to enhance transfer. Furthermore, we have shown that framing can potentially affect the transfer of multiple kinds of knowledge.

Acknowledgments This research was supported by a UC Berkeley Junior Faculty Grant, a Hellman Family Faculty Fund grant, and National Science Foundation (NSF) Grant \#0844910 to Randi A. Engle. We appreciated the students we worked with for their efforts to learn difficult academic content and their teachers for allowing us to recruit participants from their classrooms. We thank Seda Bourikian, Pegah Ghaneian, Pauline Huang, Diane Lam, Jonathan Lesser, Sarah Nix, Melissa Pandika, Sharla Roberts, Sadaf Sareshwala, Alexandra Tee, and Pamela Yee for help conducting the research. Finally, we very much appreciated the helpful advice we received at various stages from Andy Elby, James Greeno, David Hammer, Cindy Hmelo-Silver, Joanne Lobato, Jose Mestre, Kathleen Metz, Roy Pea, Daniel Schwartz, and the reviewers for Instructional Science. Of course none of these people nor the funders should be held responsible for what we say here.

Open Access This article is distributed under the terms of the Creative Commons Attribution Noncommercial License which permits any noncommercial use, distribution, and reproduction in any medium, provided the original author(s) and source are credited. 


\section{Appendix}

Propositions assessed per question

\begin{tabular}{|c|c|c|}
\hline & Core of each question pair & Propositions assessed per question pair \\
\hline \multirow[t]{2}{*}{$\begin{array}{l}\text { Differential } \\
\text { pressure } \\
\text { principle }\end{array}$} & $\begin{array}{l}\text { a. What do you think the fluid } \\
\text { pressure is like [where the fluid } \\
\text { comes from, A] as compared to } \\
\text { [where it goes to, B]? } \\
\square \text { Pressure greater in A than B } \\
\square \text { Pressure greater in B than A } \\
\square \text { Pressure same in A \& B } \\
\text { How do you think pressure gets } \\
\text { like that? }\end{array}$ & $\begin{array}{l}\text { 1. Pressure is DIFFERENT in each location* } \\
\text { 2. Pressure is LARGER in A where fluid comes from* } \\
\text { 3. Pressure implicitly CORRELATED with flow } \\
\text { 4. Pressure EXPLICITLY related to flow } \\
\text { 5. DIFFERENCES in pressure related to flow } \\
\text { 6. Flow CAUSED by difference in pressure }\end{array}$ \\
\hline & $\begin{array}{l}\text { b. In your opinion, what causes } \\
\text { [the fluid] to flow from } \\
\text { [location A] to [location B]? }\end{array}$ & $\begin{array}{l}\text { 1. PRESSURE matters } \\
\text { 2. DIFFERENCES in pressure matter } \\
\text { 3. Pressure implicitly CORRELATED with flow } \\
\text { 4. Pressure EXPLICITLY related to flow } \\
\text { 5. DIFFERENCES in pressure explicitly related to flow }\end{array}$ \\
\hline $\begin{array}{c}\text { Surface area } \\
\text { principle }\end{array}$ & $\begin{array}{l}\text { a. What, if anything, do you think } \\
\text { would happen if the many } \\
\text { small [entities with walls] were } \\
\text { replaced by a few big [entities } \\
\text { with walls] that still held the } \\
\text { same volume of [fluid]? } \\
\square \text { Exchange more efficient } \\
\square \text { Exchange less efficient } \\
\square \text { Exchange stays the same } \\
\text { Why? }\end{array}$ & $\begin{array}{l}\text { 1. EFFICIENCY of exchange is affected* } \\
\text { 2. LESS efficiency occurs* } \\
\text { 3. SURFACE AREA matters for efficiency } \\
\text { 4. COLLECTIVE surface area matters for efficiency } \\
\text { 5. DIFFERENCES in surface area matters for efficiency } \\
\text { 6. Surface area GREATER where MORE efficient } \\
\text { (or vice versa) }\end{array}$ \\
\hline & $\begin{array}{l}\text { b. Considering that so much must } \\
\text { go through [membranes], what } \\
\text { do you think are at least } 2 \\
\text { characteristics they probably } \\
\text { have? Why? }\end{array}$ & $\begin{array}{l}\text { 1. SURFACE AREA is the key characteristic } \\
\text { 2. COLLECTIVE surface area is the key characteristic } \\
\text { 3. LARGE surface area matters } \\
\text { 4. COLLECTIVE surface area needs to be LARGE } \\
\text { 5. Amount of surface area CORRELATED to amount } \\
\text { diffused }\end{array}$ \\
\hline
\end{tabular}

ALL CAPS - key aspects distinguishing the proposition from others for that response

* Based on multiple choice selection; otherwise based on written explanation

\section{References}

Ainsworth, S., \& Loizou, A. Th. (2003). The effects of self-explaining when learning with text or diagrams. Cognitive Science, 27, 669-681.

Aleven, V., Sewall, J., McLaren, B. M., \& Koedinger, K. R. (2006). Rapid authoring of intelligent tutors for real-world and experimental use. In Proceedings of the 6th IEEE international conference on advanced learning technologies (pp. 847-851), July, Kerkrade, The Netherlands.

Anderson, R. C., \& Bower, G. H. (1973). Human associative memory. New York: Wiley.

Anolli, A., Antonietti, A., Crisafulli, L., \& Cantoia, M. (2001). Accessing source information in analogical problem-solving. Quarterly Journal of Experimental Psychology, 54A(1), 237-261.

Barnett, S. M., \& Ceci, S. J. (2002). When and where do we apply what we learn? A taxonomy for far transfer. Psychological Bulletin, 128(4), 612-637.

Bateson, G. (1972). A theory of play and fantasy. In G. Bateson (Ed.), Steps to an ecology of mind: Collected essays in anthropology, psychiatry, evolution, and epistemology (pp. 177-193). New York: Ballantine. 
Bereiter, C. (1995). A dispositional view of transfer. In A. McKeough, J. Lupart, \& A. Marini (Eds.), Teaching for transfer: Fostering generalization in learning (pp. 21-34). Mahwah, NJ: Erlbaum.

Bloome, D., Power Carter, S., Morton Christian, B., Otto, S., \& Shuart-Faris, N. (2005). Discourse analysis and the study of classroom language and literacy events: A microethnographic perspective. Mahwah, NJ: Erlbaum.

Bransford, J. D., Brown, A. L., \& Cocking, R. (Eds.). (1999). Learning and transfer. In How people learn: Brain, mind, experience, and school (pp. 39-66). Washington, DC: National Academy Press.

Bransford, J. D., \& Schwartz, D. L. (1999). Rethinking transfer: A simple proposal with multiple implications. Review of Research in Education, 24, 61-100.

Brown, A. L. (1989). Analogical learning and transfer: What develops? In S. Vosniadou \& A. Ortony (Eds.), Similarity and analogical reasoning (pp. 369-412). Cambridge: Cambridge University Press.

Brown, A. L. (1992). Design experiments: Theoretical and methodological challenges in creating complex interventions in classroom settings. The Journal of Learning Sciences, 2(2), 141-178.

Campione, J. C., \& Brown, A. L. (1984). Learning ability and transfer propensity as sources of individual differences in intelligence. In P. H. Brooks, R. D. Sperber, \& C. McCauley (Eds.), Learning and cognition in the mentally retarded (pp. 265-294). Baltimore: University Park Press.

Catrambone, R. (1998). The subgoal learning model: Creating better examples so that students can solve novel problems. Journal of Experimental Psychology: General, 127(4), 355-376.

Catrambone, R., \& Holyoak, K. J. (1989). Overcoming contextual limitations on problem-solving transfer. Journal of Experimental Psychology. Learning, Memory, and Cognition, 15(6), 1147-1156.

Ceci, S. J., \& Roazzi, A. (1994). The effects of context on cognition: Postcards from Brazil. In R. J. Sternberg \& R. K. Wagner (Eds.), Mind in context: Interactionist perspectives on human intelligence (pp. 74-101). Cambridge: Cambridge University Press.

Chi, M. T. H. (2000). Self-explaining expository texts: The dual processes of generating inferences and repairing mental models. In R. Glaser (Ed.), Advances in instructional psychology (pp. 161-238). Mahwah, NJ: Erlbaum.

Chi, M. T. H., de Leeuw, N., Chiu, M.-H., \& LaVancher, C. (1994). Eliciting self-explanations improves understanding. Cognitive Science, 18, 439-477.

Chi, M. T. H., Siler, S., Jeong, H., Yamauchi, T., \& Hausmann, R. G. (2001). Learning from human tutoring. Cognitive Science, 25, 471-533.

Cobb, P., Confrey, J., diSessa, A., Lesh, R., \& Schauble, L. (2003). Design experiments in educational research. Educational Researcher, 32(1), 9-13.

Cohen, P. A., Kulik, J. A., \& Kulik, C. C. (1982). Educational outcomes of tutoring: A meta-analysis of findings. American Educational Research Journal, 19, 237-248.

Collins, A., Joseph, D., \& Bielaczyc, K. (2004). Design research: Theoretical and methodological issues. The Journal of the Learning Sciences, 13(1), 15-42.

Creider, S. (2009). Frames, footing, and teacher-initiated questions: An analysis of a beginning French class for adults. Working Papers in TESOL and Applied Linguistics, 9(2), 87-134.

Design-Based Research Collective. (2003). Design-based research: An emerging paradigm for educational inquiry. Educational Researcher, 32(1), 5-9.

Detterman, D. K. (1993). The case for the prosecution. In D. K. Detterman \& R. J. Sternberg (Eds.), Transfer on trial: Intelligence, cognition, and instruction (pp. 1-24). Norwood, NJ: Ablex.

Detterman, D. K., \& Sternberg, R. J. (Eds.). (1993). Transfer on trial: Intelligence, cognition, and instruction. Norwood, NJ: Ablex.

Engeström, Y. (2007). Enriching the theory of expansive learning: Lessons from journeys toward coconfiguration. Mind, Culture, and Activity, 14(1), 23-39.

Engle, R. A. (2006). Framing interactions to foster generative learning: A situative account of transfer in a community of learners classroom. Journal of the Learning Sciences, 15(4), 451-498.

Engle, R. A., Roberts, S., Nguyen, P. D., Yee, P., \& the Framing Transfer Research Group. (2008). A design-based approach to experimental design: Investigating hypotheses about how framing influences transfer. In P. A. Kirschner, F. Prins, V. Jonker, \& G. Kanselaar (Eds.), International perspectives in the learning sciences: Cre8ing a learning world. Proceedings of the eighth international conference of the learning sciences-ICLS 2008 (pp. 224-231). Alpharetta, GA: International Society of the Learning Sciences, Inc.

Floriani, A. (1994). Negotiating what counts: Roles and relationships, texts and contexts, content and meaning. Linguistics and Education, 5, 241-274.

Gee, J. P., \& Green, J. L. (1998). Discourse analysis, learning, and social practice: A methodological study. Review of Research in Education, 23, 119-169.

Gentner, D., Loewenstein, J., \& Thompson, L. (2003). Learning and transfer: A general role for analogical encoding. Journal of Educational Psychology, 95(2), 393-408. 
Gick, M. L., \& Holyoak, K. (1980). Analogical problem solving. Cognitive Psychology, 12, 306-355.

Gick, M. L., \& Holyoak, K. (1983). Schema induction and analogical transfer. Cognitive Psychology, 15, $1-38$.

Godden, D. R., \& Baddeley, A. D. (1975). Context-dependent memory in two natural environments: On land and underwater. British Journal of Psychology, 66(3), 325-331.

Godden, D., \& Baddeley, A. (1980). When does context influence recognition memory? British Journal of Psychology, 71(1), 99-104.

Goel, A. K., Gomez de Silva Garza, A., Grué, N., Murdock, J. W., Recker, M. M., \& Govinderaj, T. (1996). Towards designing learning environments. I: Exploring how devices work. In C. Fraisson, G. Gauthier, \& A. Lesgold (Eds.), Intelligent tutoring systems: Lecture notes in computer science. Berlin: Springer.

Goffman, E. (1974). Frame analysis: An essay on the organization of experience. New York: Harper and Row.

Goodwin, C., \& Duranti, A. (1992). Rethinking context: An introduction. In A. Duranti \& C. Goodwin (Eds.), Rethinking context: Language as interactive phenomenon (pp. 1-42). Cambridge: Cambridge University Press.

Graesser, A. C., Person, N. K., \& Magliano, J. P. (1995). Collaborative dialogue patterns in naturalistic oneto-one tutoring. Applied Cognitive Psychology, 9(6), 495-522.

Greeno, J. G. (2006). Authoritative, accountable positioning and connected, general knowing: Progressive themes in understanding transfer. Journal of the Learning Sciences, 15(4), 537-547.

Greeno, J. G., Smith, D. R., \& Moore, J. L. (1993). Transfer of situated learning. In D. K. Detterman \& R. J. Sternberg (Eds.), Transfer on trial: Intelligence, cognition, and instruction (pp. 99-127). Norwood, NJ: Ablex.

Gumperz, J. J. (1982). Contextualization conventions. In Discourse strategies (pp. 130-152). Cambridge: Cambridge University Press.

Gumperz, J. J. (1992). Contextualization and understanding. In A. Duranti \& C. Goodwin (Eds.), Rethinking context (pp. 229-252). Cambridge: Cambridge University Press.

Hammer, D., Elby, A., Scherr, R. E., \& Redish, E. F. (2005). Resources, framing, and transfer. In J. Mestre (Ed.), Transfer of learning: Research and perspectives (pp. 89-119). Greenwich, CT: Information Age Publishing.

Hart, W., \& Albarracin, D. (2009). What was doing vs. what I did: Verb aspect influences memory and future actions. Psychological Science, 20(2), 238-244.

Hausmann, R. G. M., \& vanLehn, K. (2007). Explaining self-explaining: A contrast between content versus generation. In R. Luckin, K. R. Koedinger, \& J. E. Greer (Eds.), Artificial intelligence in education: Building technology rich learning contexts that work (pp. 417-424). Amsterdam: IOS Press.

Hmelo-Silver, C. E., Marathe, S., \& Liu, L. (2007). Fish swim, rocks sit, and lungs breathe: Expert-novice understanding of complex systems. The Journal of the Learning Sciences, 16, 307-331.

Hmelo-Silver, C. E., \& Pfeffer, M. G. (2004). Comparing expert and novice understanding of a complex system from the perspective of structures, behaviors, and functions. Cognitive Science, 28, 127-138.

Hymes, D. (1972). Models of the interaction of language and social life. In J. Gumperz \& D. Hymes (Eds.), Directions in sociolinguistics: The ethnography of communication (pp. 35-71). New York: Holt, Rinehart \& Winston.

Judd, C. H. (1908). The relation of special training to general intelligence. Educational Review, 36, $28-42$.

Laboratory of Comparative Human Cognition. (1983). Culture and cognitive development. In P. H. Mussen (Ed.), Handbook of child psychology: Vol. 1. History, theory and methods (pp. 295-356). New York: Wiley.

Lave, J. (1988). Cognition in practice: Mind, mathematics, and culture in everyday life. New York: Cambridge University Press.

Leander, K. M. (2001). "This is our freedom bus going home right now": Producing and hybridizing spacetime contexts in pedagogical discourse. Journal of Literacy Research, 33(4), 637-679.

Lemke, J. (2001). Articulating communities: Sociocultural perspectives on science education. Journal of Research in Science Teaching, 38(3), 296-316.

Lobato, J. (2006). Alternative perspectives on the transfer of learning: History, issues, and challenges for future research. Journal of the Learning Sciences, 15(4), 431-449.

Loewenstein, J. (2010). How one's hook is baited matters for catching an analogy. In B. Ross (Ed.), The psychology of learning and motivation: Advances in research and theory (Vol. 53, pp. 149-182). New York: Academic Press.

Lui, L., \& Hmelo-Silver, C. E. (2009). Promoting complex systems learning through the use of conceptual representations in hypermedia. Journal of Research in Science Teaching, 46(9), 1023-1040.

Macaulay, D. (1988). Binoculars. In The way things work (p. 202). Boston: Houghton-Mifflin. 
McCandliss, B. D., Kalchman, M., \& Bryant, P. (2003). Design experiments and laboratory approaches to learning: Steps towards collaborative exchange. Educational Researcher, 32(1), 14-16.

McNamara, D. (2004). SERT: Self-explanation reading training. Discourse Processes, 38(1), 1-30.

Mestre, J. (2003). Transfer of learning: Issues and research agenda: Report of a workshop held at the National Science Foundation. Arlington, VA: National Science Foundation. http://www.nsf.gov/pubs/ 2003/nsf03212/nsf03212.pdf.

Michael, J. A., Wenderoth, M. P., Modell, H. I., Cliff, W., Hortwitz, B., McHale, P., et al. (2002). Undergraduates' understanding of cardiovascular phenomena. Advances in physiology education, 26(2), 72-84.

Minsky, M. (1975). Minsky's frame system theory. In B. L. Nash-Webber \& R. Schank (Eds.), Theoretical issues in natural language processing (pp. 104-116). Morristown, NJ: Association for Computational Linguistics.

Murphy, G. (2002). The big book of concepts. Cambridge, MA: MIT Press.

O'Connor, M. C., \& Michaels, S. (1996). Shifting participant frameworks: Orchestrating thinking practices in group discussion. In D. Hicks (Ed.), Discourse, learning, and schooling (pp. 63-103). New York: Cambridge University Press.

Odom, A. L., \& Barrow, L. H. (1995). Development and application of a two-tier diagnostic test measuring college biology students' understanding of diffusion and osmosis after a course of instruction. Journal of Research in Science Teaching, 32, 45-61.

Odom, A. L., \& Barrow, L. H. (2007). High school biology students' knowledge and certainty about diffusion and osmosis concepts. School Science and Mathematics, 107(3), 94-101.

Pace, J. L., \& Hemmings, A. (2007). Understanding authority in classrooms: A review of theory, ideology, and research. Review of Educational Research, 77(1), 4-27.

Pea, R. D. (1987). Socializing the knowledge transfer problem. International Journal of Educational Research, 11, 639-663.

Pugh, K. J., \& Bergin, D. A. (2006). Motivational influences on transfer. Educational Psychologist, 41(3), $147-160$.

Putney, L. G., Green, J., Dixon, C., Duran, R., \& Yeager, B. (2000). Consequential progressions: Exploring collective-individual development in bilingual classrooms. In C. D. Lee \& P. Smagorinsky (Eds.), Vygotskian perspectives on literacy research: Constructing meaning through collaborative inquiry (pp. 86-126). Cambridge: Cambridge University Press.

Reed, S. K. (1993). A schema-based theory of transfer. In D. K. Detterman \& R. J. Sternberg (Eds.), Transfer on trial: Intelligence, cognition and instruction (pp. 39-67). Norwood, NJ: Ablex.

Reeves, L. M., \& Weisberg, R. W. (1993). On the concrete nature of human thinking: Content and context in analogical transfer. Educational Psychology, 13(3/4), 245-258.

Reeves, L. M., \& Weisberg, R. W. (1994). The role of content and abstract information in analogical transfer. Psychological Bulletin, 115(3), 381-400.

Renkema, J. (2004). Structured content. In Introduction to discourse studies (pp. 87-102). Amsterdam: John Benjamins.

Rittle-Johnson, B. (2006). Promoting transfer: Effects of self-explanation and direct instruction. Child Development, 77(1), 1-15.

Rittle-Johnson, B., \& Star, J. R. (2007). Does comparing solution methods facilitate conceptual and procedural knowledge? An experimental study on learning to solve equations. Journal of Educational Psychology, 99(3), 561-574.

Ross, B. H. (1984). Reminding and their effects in learning a cognitive skill. Cognitive Psychology, 16(3), $371-416$.

Salomon, G., \& Perkins, D. N. (1989). Rocky roads to transfer: Rethinking mechanisms of a neglected phenomenon. Educational Psychologist, 24(2), 113-142.

Schegloff, E. (1993). Reflections on quantification in the study of conversation. Journal of Language and Social Interaction, 26(1), 99-128.

Schwartz, D. L., Bransford, J. D., \& Sears, D. (2005). Efficiency and innovation in transfer. In J. Mestre (Ed.), Transfer of learning: Research and perspectives. Greenwich, CT: Information Age Publishing.

Schwartz, D. L., \& Nasir, N. (2003). Transfer of learning. In J. W. Guthrie (Ed.), Encyclopedia of education (2nd ed., Vol. 4, pp. 1449-1452). New York: Macmillan.

Searle, J. R. (1995). The construction of social reality. New York: Simon and Schuster.

Shadish, W., Cook, T., \& Campbell, D. (2002). Experimental and quasi-experimental design for generalized causal inference. New York: Houghton-Mifflin.

Shulman, L. S. (1992). Toward a pedagogy of cases. In J. H. Shulman (Ed.), Case methods in teacher education (pp. 1-30). New York: Teachers College Press. 
Smith, S. M., Glenberg, A., \& Bjork, R. A. (1978). Environmental context and human memory. Memory and Cognition, 6(4), 342-353.

Spencer, R. M., \& Weisberg, R. W. (1986). Context-dependent effects on analogical transfer. Memory and Cognition, 14, 442-449.

Tannen, D. (1993). Introduction. In D. Tannen (Ed.), Framing in discourse (pp. 3-13). New York: Oxford University Press.

Tannen, D., \& Wallet, C. (1987). Interactive frames and knowledge schemas in interaction: Examples from a medical examination/interview. Social Psychology Quarterly, 50(2), 205-216.

Thorndike, E. L. (1903/2009). Educational psychology. Charleston, SC: BiblioLife, LLC.

Thorndike, E. L., \& Woodworth, R. S. (1901). The influence of improvement in one mental function upon the efficiency of other functions. Psychological Review, 8, 247-261.

Tukey, J. W. (1953). Some selected quick and easy methods of statistical analysis. Transactions of the New York Academy of Sciences, 16(2), 88-97.

Tulving, E., \& Thomson, D. M. (1973). Encoding specificity and retrieval processes in episodic memory. Psychological Review, 80, 353-370.

van Dijk, T. A. (2008). Discourse and context: A sociocognitive approach. New York: Cambridge University Press.

van Dijk, T. A., \& Kintsch, W. (1983). Strategies of discourse comprehension. New York: Academic Press.

VanLehn, K., Siler, S., Murray, C., Yamauchi, T., \& Baggett, W. B. (2003). Why do only some events cause learning during human tutoring? Cognition and Instruction, 21(3), 209-249.

Wagner, J. (2006). Transfer in pieces. Cognition and Instruction, 24(1), 1-71.

Yip, D. Y. (1998). Teachers' misconceptions of the circulatory system. Journal of Biological Education, 32(3), 207-215. 